\title{
Structural set-up of Southern Sinai and Gulf of Suez areas indicated by geophysical data
}

\author{
Taha Rabeh \\ National Research Institute of Astronomy and Geophysics (NRIAG), \\ Geophysical Department, Helwan, Cairo, Egypt
}

\begin{abstract}
This work deals with the evaluation of the structural set-up of the southern part of Sinai Peninsula, Gulf of Suez and western part of Gulf of Suez from magnetic, gravity, and seismic data. The utilised techniques including the Least Squares separation method suggest NW, NE, and E-W trends. The trend analysis shows north $35^{\circ}-45^{\circ}$ west, north $15^{\circ}-25^{\circ}$ east and E-W which may be related to the Gulf of Suez and Red Sea stresses.The Euler deconvolution illustrates that the area is highly affected by these trends. Depths range from $1 \mathrm{~km}$ to more than $3 \mathrm{~km}$ below sea level and its magnetic susceptibility ranges between 1 to 3 SI units. The 2.5D magnetic modelling and analytical signal techniques confirm the depths to the magnetic sources deduced by the Euler method, whereas the depth to the basement rocks ranges between $0 \mathrm{~km}$ to about $3 \mathrm{~km}$ indicating that it is subjected to strong tectonic activities. In addition, two seismic sections (EG-31 and MP-70), compiled by the Egyptian General Petroleum Cooperation (EGPC), were interpreted together with a geologic cross section. The studied area may be divided into several major blocks along the Gulf of Suez area. It can be concluded that the sedimentary was affected by basement tectonics as revealed by the two seismic sections.
\end{abstract}

Key words geomagnetic survey - sub-surface structures - aeromagnetic data - seismic lines

\section{Introduction}

The studied area lies in the southern part of the Sinai Peninsula, Gulf of Suez and northern part of the Eastern Desert (fig. 1) between latitudes $27^{\circ} 50^{\prime}$ and $30^{\circ} 05^{\prime}$ north and longitudes $32^{\circ} 48^{\prime}$ and $34^{\circ} 23^{\prime}$ east covering an area of about $24000 \mathrm{~km}^{2}$. It is a Tertiary cratonic rift south of Egypt's Sinai Peninsula between North-Eastern Africa and the Arabian Peninsu-

Mailing address: Dr. Taha Rabeh, National Research Institute of Astronomy and Geophysics (NRIAG), Geophysical Department, Helwan, Cairo, Egypt; e-mail: taharabeh@yahoo.com la. The rifting essentially ceased (Early-Middle Miocene, 18-14 Myr) when continental separation became more oblique because of the dominant movement on the left-lateral transform fault that extends through the Gulf of Aqaba north-eastward to the Dead Sea (Patton et al., 1994; Lindquist, 1998).

The tectonics of this area has been constructed using different geophysical tools (e.g., aeromagnetic, land magnetic gravity, and seismic).

These tectonics were analyzed from deep depths to show depths along the studied area.

\section{Geology of the area}

The Red Sea, Gulf of Suez basins consists of a high faulted block more than $100000 \mathrm{~km}^{2}$ in size that contains block-faulted trapping configurations in the Gulf of Suez. This unit in- 


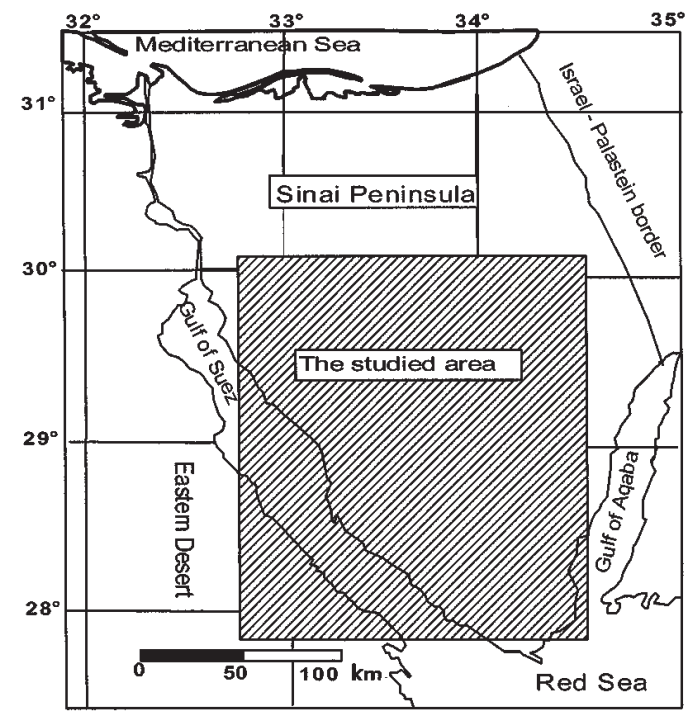

Fig. 1. Location map of the studied area. cludes coastal areas of the Red Sea and the Southern Gulf of Suez.

The geology of the area ranges from Precambrian basement rocks to the Quaternary deposits. According to the Egyptian Geological Survey map (EGSMA, 1993) (fig. 2), the Quaternary deposits cover the basement rocks along the Gulf of Suez and Gulf of Aqaba.

The basement rocks (Precambrian) occupy the southern part of the studied area, along the Gulf of Suez and Gulf of Aqaba. On the other hand, the Palaeozoic rocks are present in the middle part while the Mesozoic rocks covered the eastern and western parts of the area.

Furthermore, a geologic cross section was constructed (fig. 4), using the most updated borehole data. This section was performed crossing Gulf of Suez taking a northeast-southwest direction. It indicates that the depth to the basement rocks varies from $0 \mathrm{~km}$ to more than $3 \mathrm{~km}$. The basement rocks consist of major

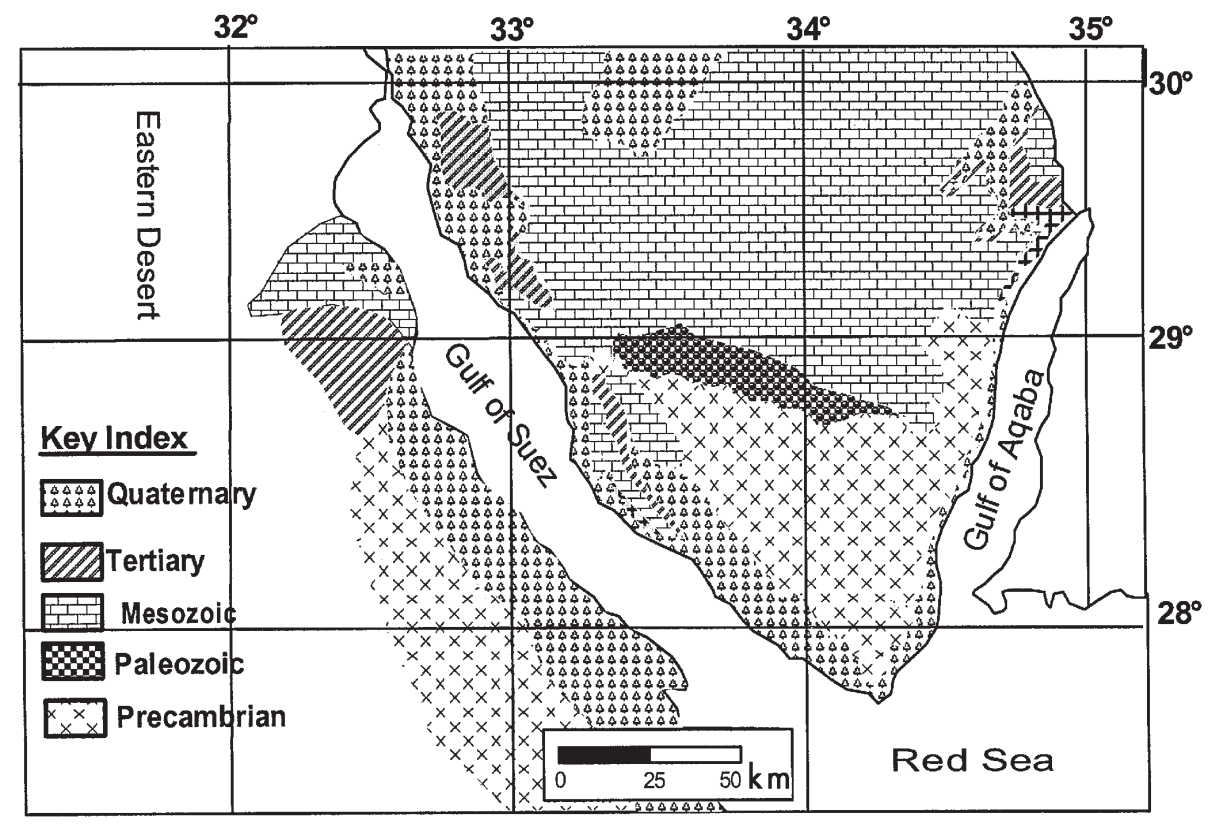

Fig. 2. Geological map of the studied area (EGSMA, 1993). 


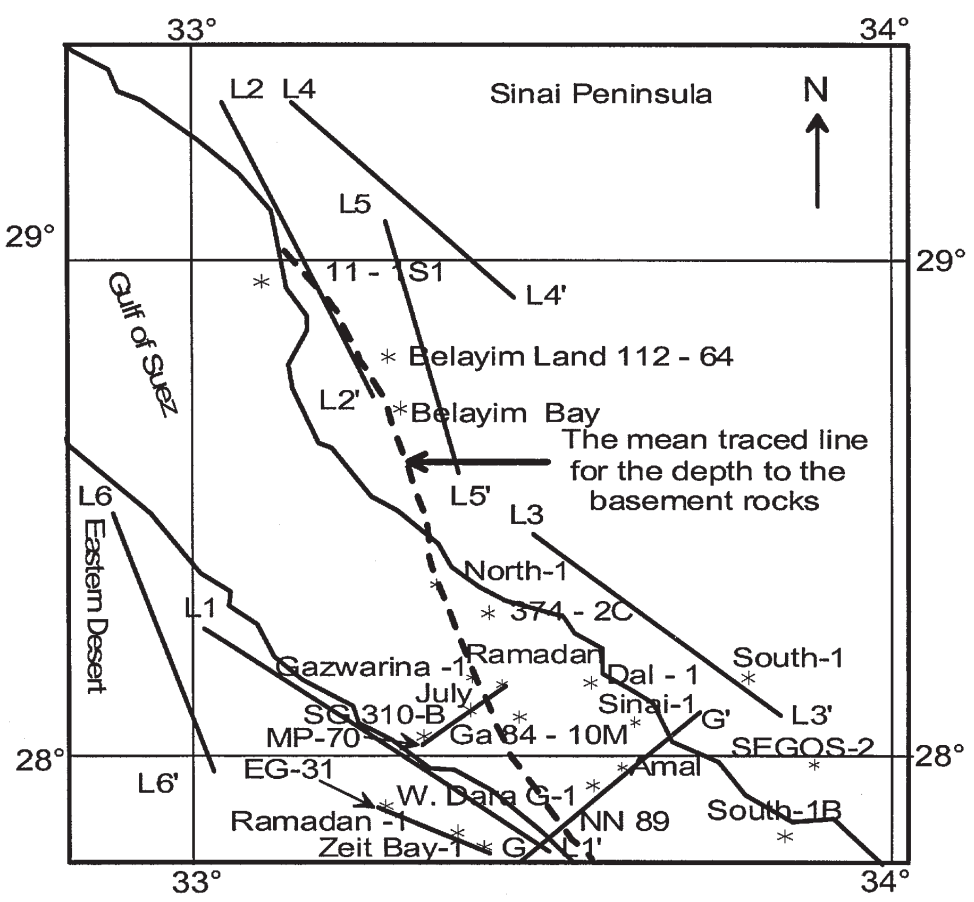

Fig. 3. Location of the drilled wells, the two seismic lines and profiles of land magnetic survey (L-L').

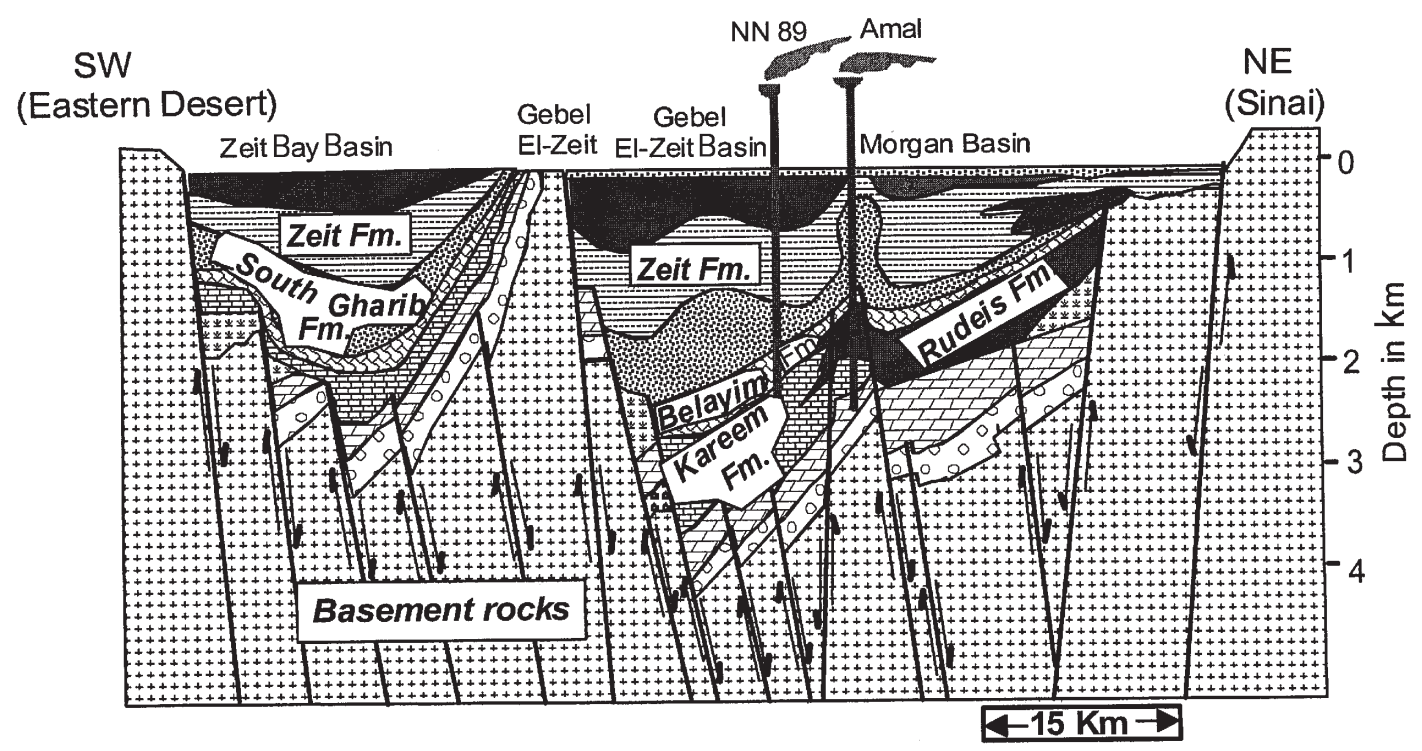

Fig. 4. Geologic cross section along profile G-G' crossing the Gulf of Suez. 


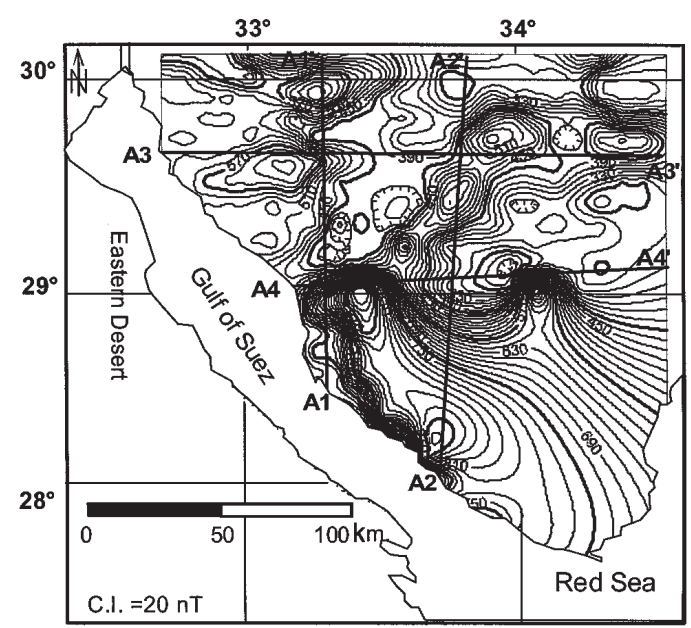

- Profiles used for aplications of Euler, 2D and depth stmation methods

Fig. 5. RTP aeromagnetic anomaly map of the studied area (EGPC, 1990).

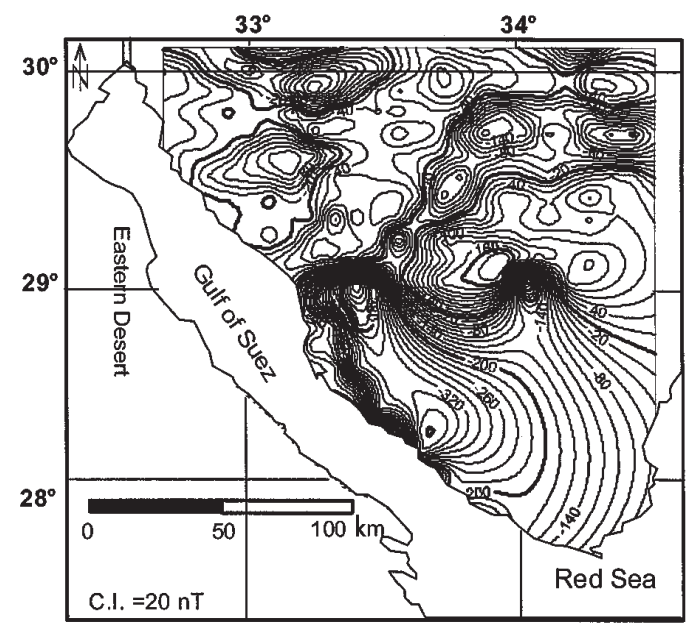

Fig. 7. Least square residual RTP aeromagnetic map (2nd order).

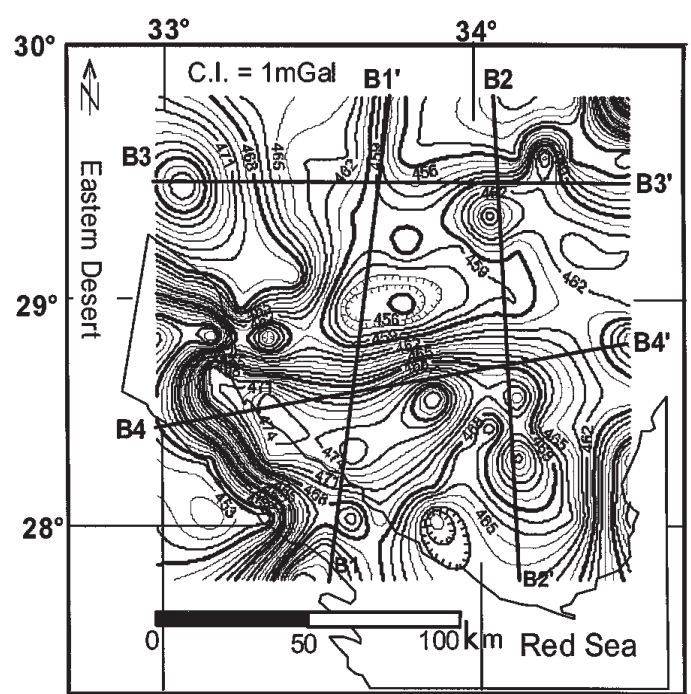

- Profiles used for aplications of Euler, 2D and depth estmation methods

Fig. 6. Bouguer anomaly map of the studied area (after IPRG, ca. 1982).

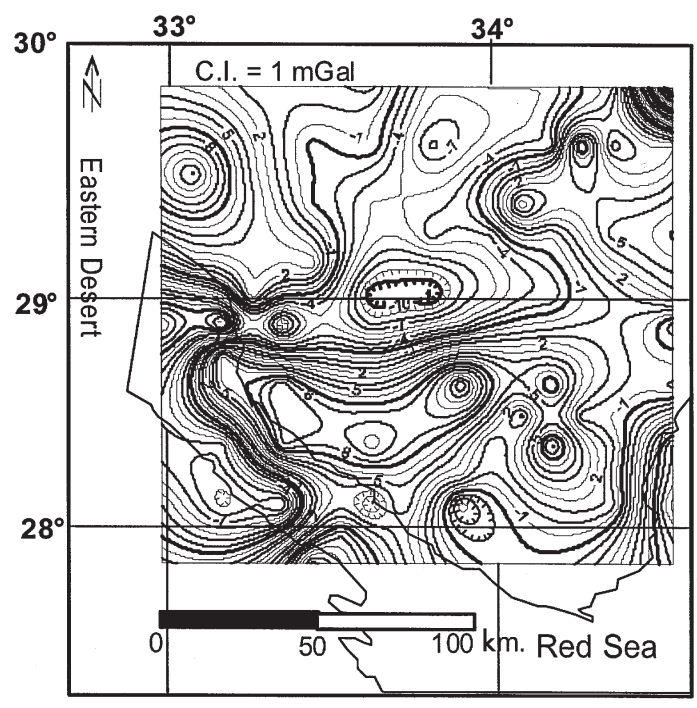

Fig. 8. Least square residual Bouguer anomaly map (2nd order). 
faulted blocks along the Gulf of Suez. The depth to the carrier reservoir bed (Belayim Fm.) varies from about $2 \mathrm{~km}$ to about $3 \mathrm{~km}$.

\section{Data analysis and interpretations}

The land magnetic survey was performed using two magnetic Protons of Geometric type. One instrument is used as a base station for diurnal corrections for each profile, and the second is used to measure the observed magnetic data. The land survey was performed in the form of profiles along the Gulf of Suez area, (fig. 3). The distance between the stations ranges from 200 to $300 \mathrm{~m}$ according to the changes in the recorded geomagnetic data.

The aeromagnetic map was prepared by the EGPC (1990) with a flight elevation of $1 \mathrm{~km}$. The aeromagnetic data was digitized into a computer using a suitable Surfer Program v. 8.00 (Surfer, 2002). Both land magnetic data and the aeromagnetic data were reduced to the North Magnetic Pole (Hansen and Pawlowski, 1989), to obtain the RTP magnetic anomaly map (fig. 5).

Both the RTP aeromagnetic (fig. 5) and Bouguer Anomaly maps (fig. 6) indicate that most anomalies are aligned to NW, NE, and EW which may be related to the Gulf of Suez, and Gulf of Aqaba. The negative anomalies in the central part may be due to lithology variation of the basement.

The Bouguer Anomaly map (IPRG, ca. 1982) was digitized and contoured at $1 \mathrm{mGal}$ (fig. 6). This map conforms to the observed RTP anomalies (fig. 5). It reveals a gravity lows in the central and southern parts. These alternative negative and positive anomalies along the Gulf of Suez may be due to the faulted blocks or presence of different basins with different thickness of sedimentary sequence in the area. This leads to the conclusion that the shallow parts are extending along the two Gulfs and southern part of Sinai where the basement rocks are outcropping (fig. 2).

\section{Least squared residual technique}

The Least Square method of Henderson (1966) was applied to the RTP magnetic Bouguer maps using first, second, and third order fitted to the input magnetic and gravity data. This method was applied using the software Surfer v. 7.00 (Surfer, 1997). The correlation coefficients between successive residual maps were computed to determine the optimum order of the regional surface to be used. Results were

$$
r_{21}=0.854, r_{21}=0.96 \text { and } r_{34}=0.546 \text {. }
$$

According to Davis (1973), a correlation factor higher than 0.7 indicates a good similarity between maps, the regional field in this area can be represented by a second-order surface, and the polynomial used has the form

$$
\begin{aligned}
& (x, y)^{2}=-7.947-0.4778 y+0.065 x+ \\
& +0.08144 y-0.03575 x y-0.002528 x .
\end{aligned}
$$

The resulting least-squared residual maps of second-order (figs. 7 and 8) show that most of the anomalies are the same trends trending north west-south east, north east-south west and eastwest directions. Also, it can be concluded that most of these anomalies are related to different blocks with different polarities and structures. Furthermore these maps represent the best fitted maps to the original RTP aeromagnetic and Bouguer anomaly maps.

\section{Trend analysis technique}

A two lineaments map (fig. 9) was constructed from application of the trend analysis technique (Grant et al., 1965; Parasnis, 1997) for the RTP aeromagnetic and Bouguer anomalies maps. This map was subjected to statistical calculating for the lengths percentages of the faults measured clockwise from the north.

The deduced lineation of different directions are grouped every $10^{\circ}$ around the north for their length percentage (L\%). A statistical procedure was used to illustrate the predominant fault trends affecting the studied area.

The results of azimuth distribution of both surface and subsurface elements are presented in the form of a rose diagram (fig. 10). The results show that the most predominant direction is north $35^{\circ}-45^{\circ}$ west, north $45^{\circ}-65^{\circ}$ east, eastwest and Aqaba trends. It is clear that the main 


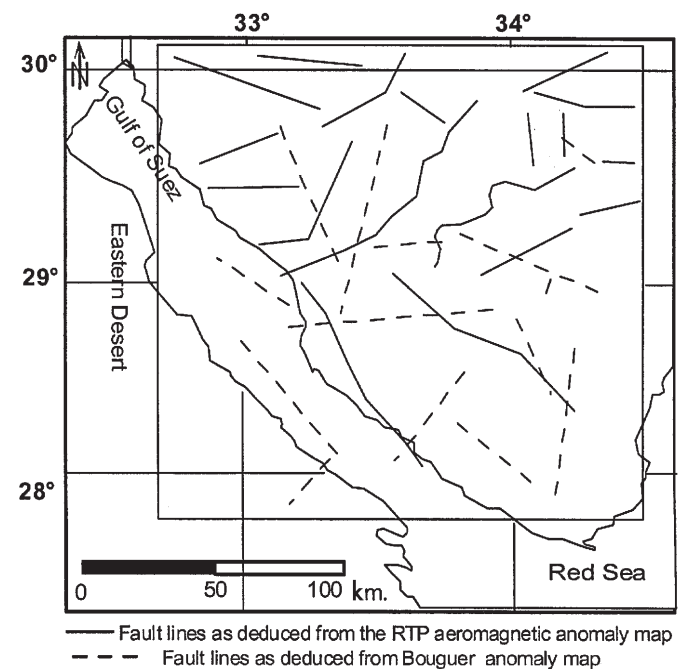

Fig. 9. Tectonic lines as deduced from the RTP aeromagnetic and Bouguer anomaly maps.

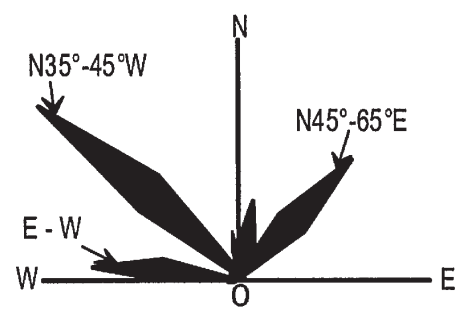

L\% of the Bouguer anomaly map

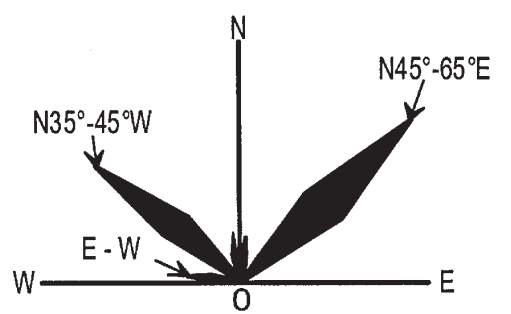

L\% of the RTP aeromagnetic map

Fig. 10. Rose diagrams illustrate the distribution of the lengths percentage (L\%) of faults against azimuth. tectonic trend is north $35^{\circ}-45^{\circ}$ west prevailing for the large scale in both the Bouguer and RTP aeromagnetic maps. This may be due to a very strong and active force resulting from the opening of the Gulf of Suez. The second predominant tectonic force is north $45^{\circ}-65^{\circ}$ east that is probably due to the Syrian Arc system. The least predominant is the north $15^{\circ}-25^{\circ}$ east due to tectonics related to the Gulf of Aqaba.

\section{Euler deconvolution method}

The two-dimensional Euler technique is a method that uses the horizontal and vertical derivatives of the total magnetic field to estimate the location and depth to magnetic sources (Thompson, 1982; Reid et al., 1990). This method has been applied to the magnetic profiles along the area (figs. 11 and 12).

Applying Euler deconvolution to the vertical gradient of the total magnetic field data provides improved source resolution (Stavrev, 1997; Hsu, 2002)

$$
\begin{aligned}
\frac{\partial}{\partial x}\left(\frac{\partial^{n} f}{\partial z^{n}}\right) & \left(x-x_{0}\right)+\frac{\partial}{\partial x}\left(\frac{\partial^{n} f}{\partial z^{n}}\right)\left(z-z_{0}\right)= \\
= & \text { SI }\left(\Delta\left(\frac{\partial^{n} f}{\partial z^{n}}\right)+B_{z}\right)
\end{aligned}
$$

where $n$ is the order (which is not necessarily an integer (Cooper and Cowan, 2003)) of the gradient used. It may similarly be applied to the horizontal gradient

$$
\begin{gathered}
\frac{\partial}{\partial x}\left(\frac{\partial^{n} f}{\partial z^{n}}\right)\left(x-x_{0}\right)+\frac{\partial}{\partial z}\left(\frac{\partial^{n} f}{\partial x^{n}}\right)\left(z-z_{0}\right)= \\
=\operatorname{SI}\left(\Delta\left(\frac{\partial^{n} f}{\partial x^{n}}\right)+B_{x}\right)
\end{gathered}
$$

In general the magnetic field falls off as $r-N$ with $r=\left(x^{2}+z^{2}\right)^{1 / 2}$. The parameter $x$ is the location of the magnetic source along the magnetic profile and $z$ is the depth to the top of the magnetic source (Thompson, 1982). The value of $N$, called the structural index, depends on the shape of the magnetic source. For example, $N=3$ corresponds to a three-dimensional body such as a sphere while a 


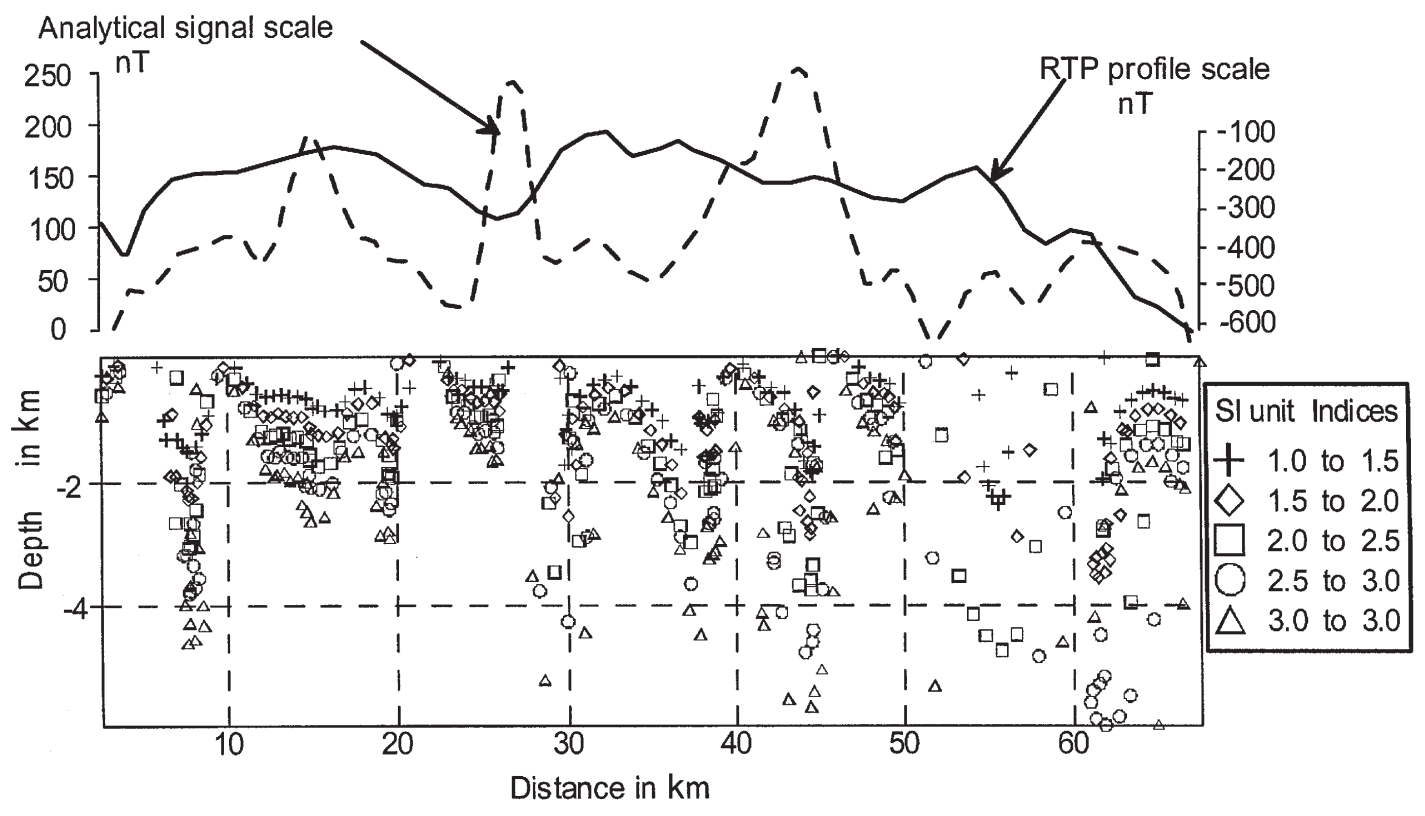

Fig. 11. Euler deconvolution along L1-L1' of the land magnetic data.

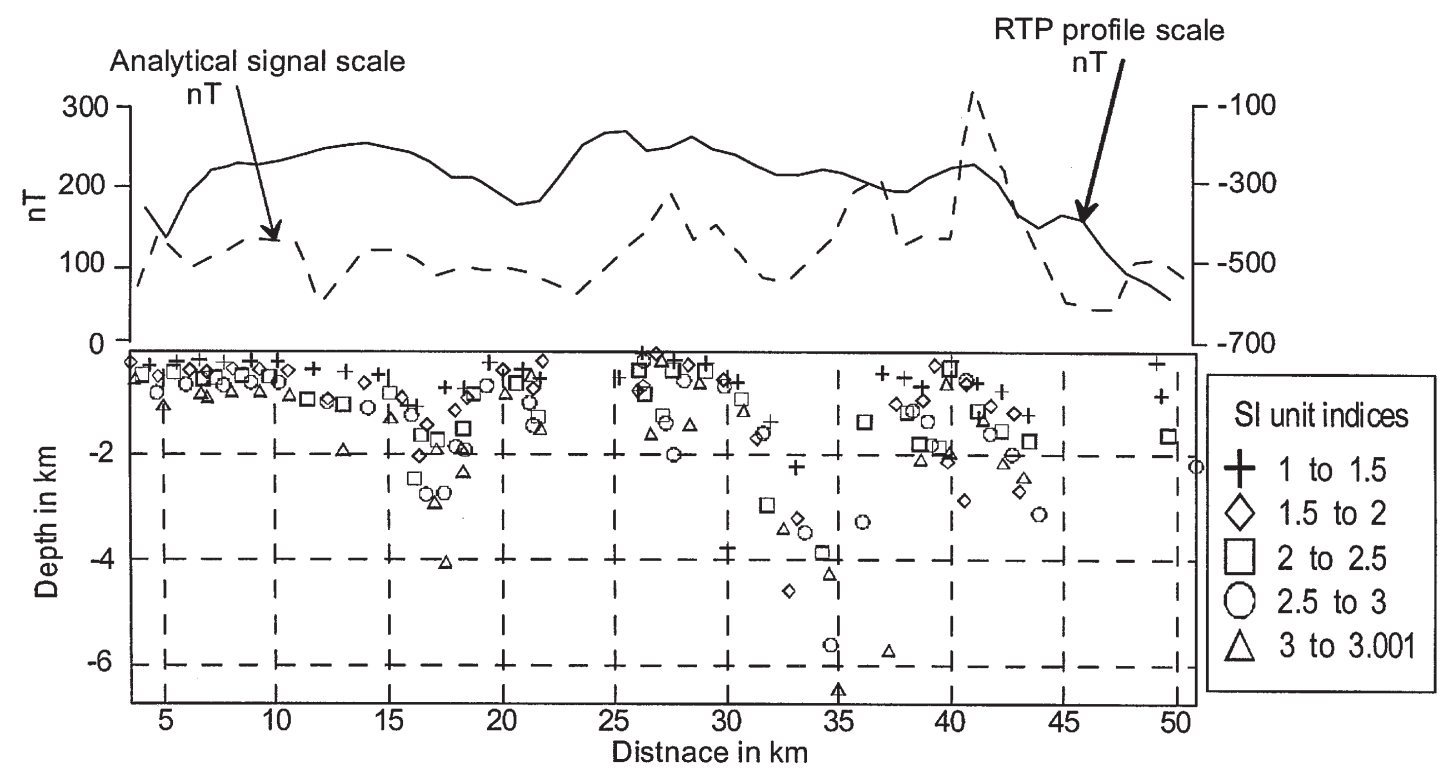

Fig. 12. Euler deconvolution along L3-L3' of the land magnetic data. 
two-dimensional dike corresponds to $N=2$. Values of $N$ between 1 and 0.5 correspond to two-dimensional faults and contacts. The depth to the structures depends on structural index $N$ and the size of the applied sliding window.

The Euler deconvolution method has been applied to the aeromagnetic using 0 magnetic contact index: to determine the depths to the irregular magnetic bodies, 0.5 magnetic step index in order to indicate the depth to the basement rocks and their structures and 1 dike index for delineating the depth to the anomalies caused by vertical thin dykes.

Most the results derived from the Euler deconvolution method indicate that area is highly affected by the regional forces related to the Gulf of Suez, and Red Sea tectonics. It is indicated by the different position and depths of the sources of the subsurface magnetic bodies (figs. 11 and 12), which consist of dissected bodies along these profiles. Also, it can be stated that these magnetic sources are restricted by tectonic trends have NW-SE and NE-SW directions (fig. 13). These structures were confirmed by the analytical signal applied to the same profiles.

The magnetic susceptibility of the rocks ranges between 1 to 3 SI units whereas their depths range between $1 \mathrm{~km}$ to about $4 \mathrm{~km}$. These wide ranges in the depth to the subsurface basement rocks are due to the highly faulted areas.

\section{Application of the analytical signal and depth estimation methods}

The analytical signal was performed along the same profiles interpreted by the Euler method by Reid et al. (1990) using Nabighian's technique (Nabighian, 1972, 1984). It is applied to confirm the results deduced from the Euler method (figs. 12 and 13). The spikes of the analytical signal profile are an indication for the subsurface structures. The presence of one spike indication of subsurface fault structure, and the presence of two closed spikes are due to the presence of subsurface dike, the high amplitude spike for the near edge of the dike and the small amplitude spike is due to the lower edge of the dike.

Also, the depth to the magnetic sources was applied to the analytical signal using (Atchuta

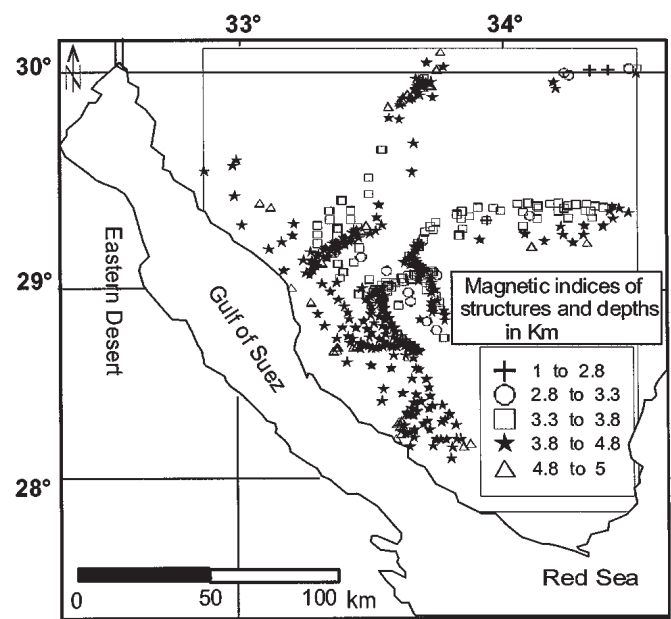

Fig. 13. Applications of Euler deconvolution to the aeromagnetic map.

et al., 1981; Roest et al., 1992). The depth to the magnetic sources equals half of the amplitude of the analytical signal. This method had been applied to amplitudes along the profiles.

The results confirm the parameters deduced from the Euler method. The depth to these bodies ranges between $0.5 \mathrm{~km}$ to more than $3 \mathrm{~km}$.

\section{Application of 2.5D modelling}

Computations of the magnetic effects for 2.5D models with complex geometry were carried out using the GM-SYS computer program produced by Northwest Geophysical Associates Inc. (GM-SYS, 1995), for the arbitrary two-dimensional polygon. This type of modeling is a reverse model that depends on the changes in the magnetic susceptibility, or the density contrasts of the sedimentary rocks and the depth parameters till complete matching between the calculated and observed profiles (fig. 14). The resulting parameters represent the main target of this method (e.g., depth, magnetic susceptibility, etc.).

This 2.5D model confirms the depths to the magnetic sources deduced by the Euler method. It can be noticed from (fig. 14) that the depth to the 


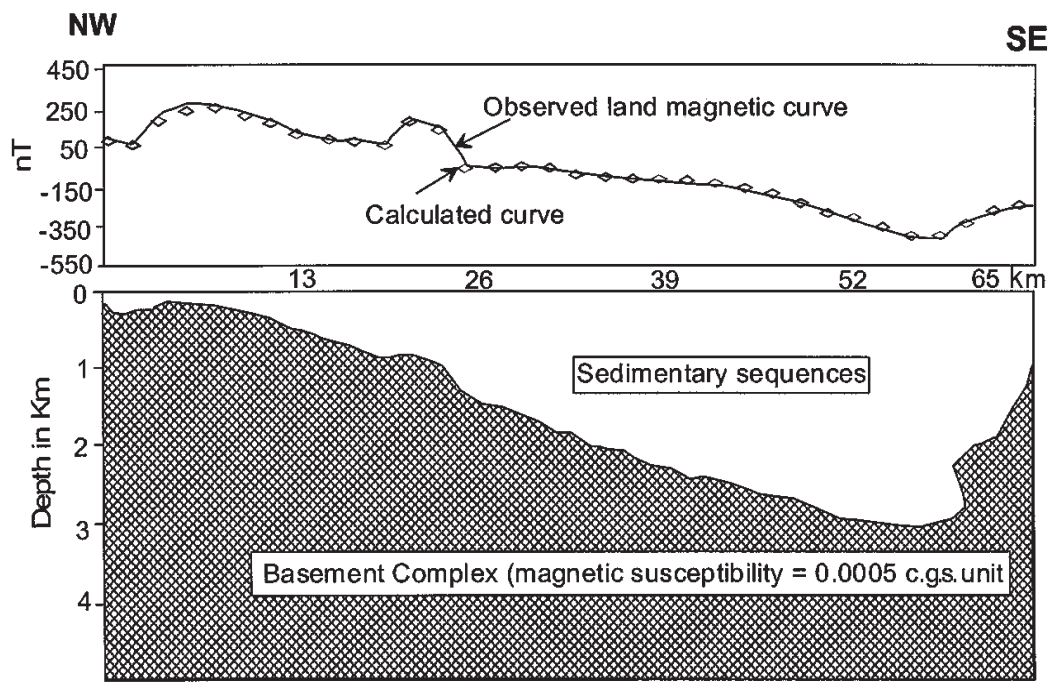

Fig. 14. 2.5D modelling along $\mathrm{L} 1-\mathrm{L}^{\prime}$ ' of the land magnetic profile.

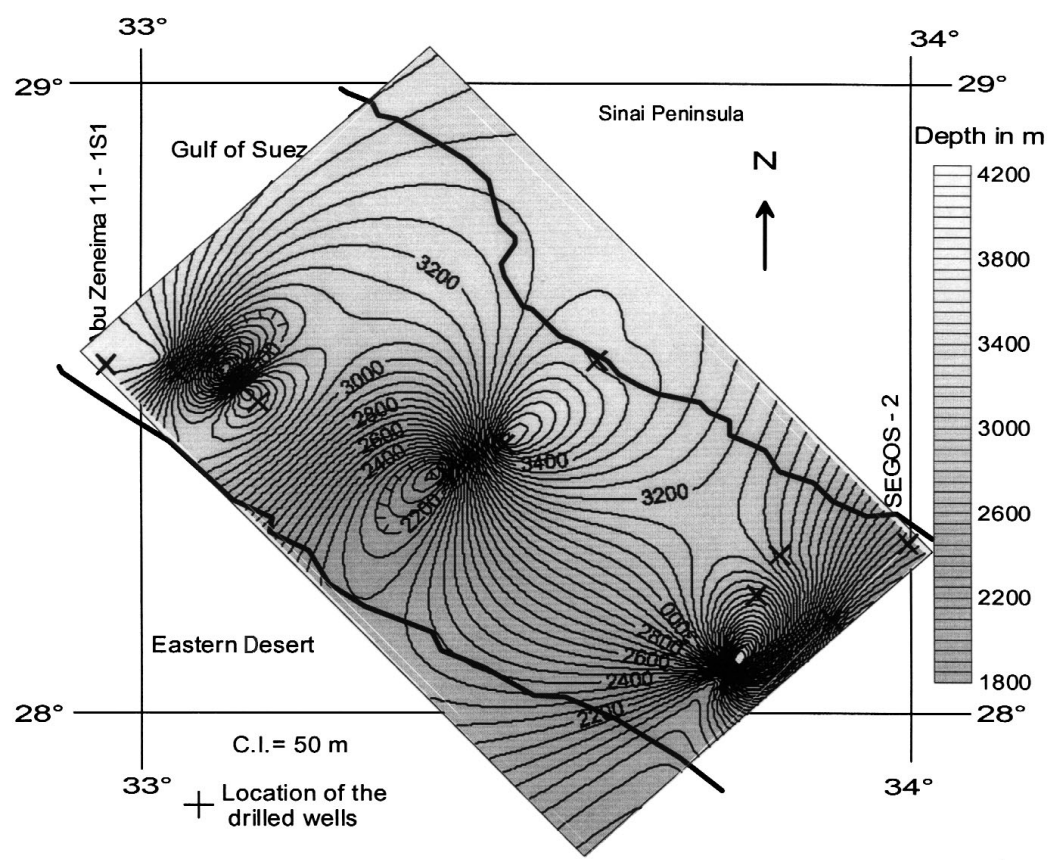

Fig. 15. The depth to the basement rocks along the Gulf of Suez area, derived from the wells drilled in the area. 

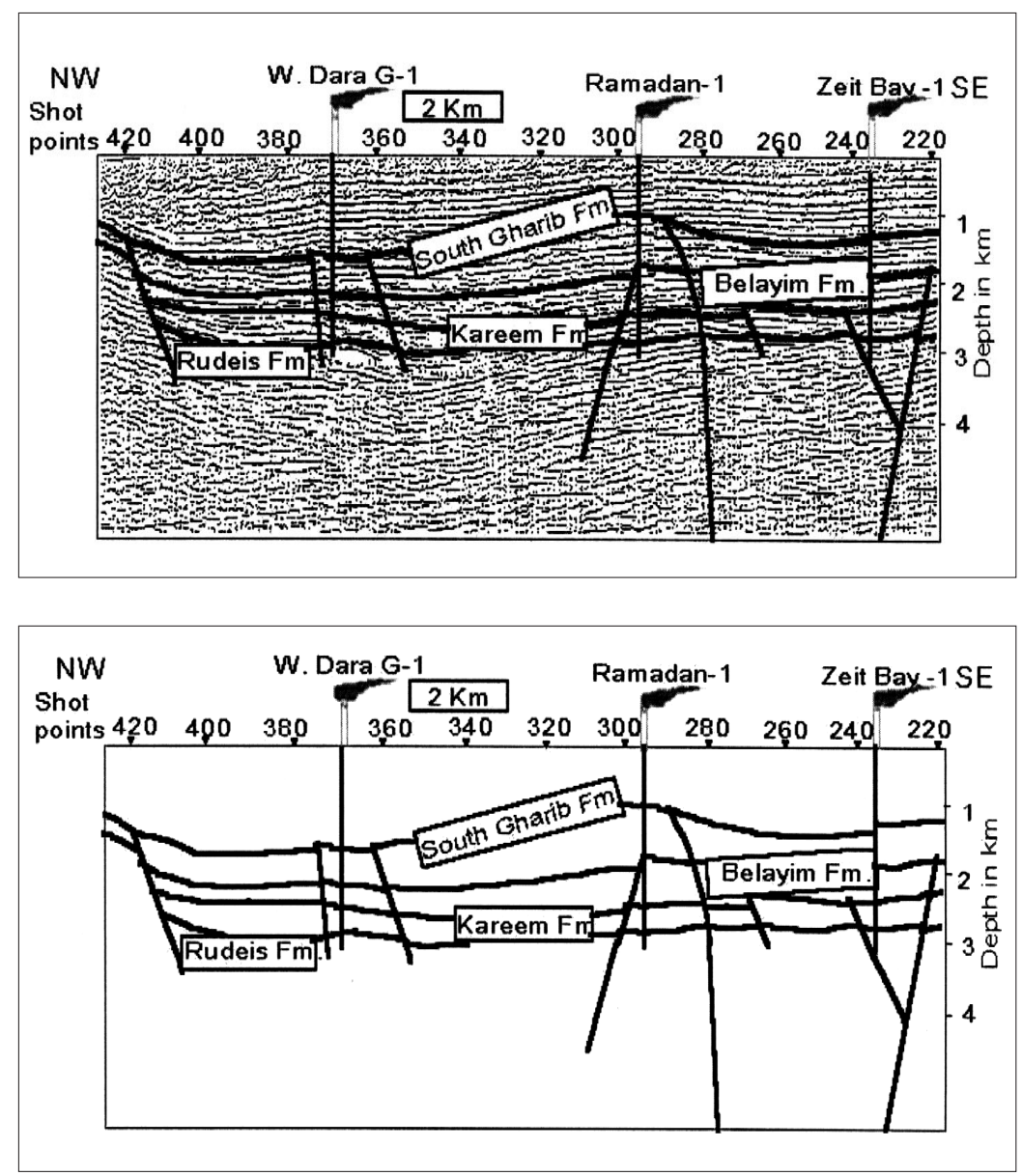

Fig. 16. Interpretation along seismic line EG-31 western side of Gulf of Suez.

basement rocks ranges between $0 \mathrm{~km}$ to about $3 \mathrm{~km}$ while the magnetic susceptibility reaches about 0.0005 CGS unit. Also, it is obvious that this result is correlated with the results deduced by the Euler deconvolution and analytical signal method.

\section{Depth to the basement rocks using well logging data}

The depth to the basement rocks along the Gulf of Suez from north to south direction was traced, using the most recent wells data (EGPC,
2000) drilled to the basement rocks in the studied area. Figure 15 indicates that the depth to the basement rocks varies widely from less than $2 \mathrm{~km}$ at the north western part to more than 3 $\mathrm{km}$ at the eastern part of the Gulf. This may be due to the controlling structures related to Gulf of Suez tectonics. These results conform with the RTP magnetic, gravity and geologic crosssection showing the wide variations of the depth along the Gulf of Suez. Thus it is clear that the Gulf of Suez consists of different faulted blocks forming the uplifted basement, and the deep basins. This emerges from the results 

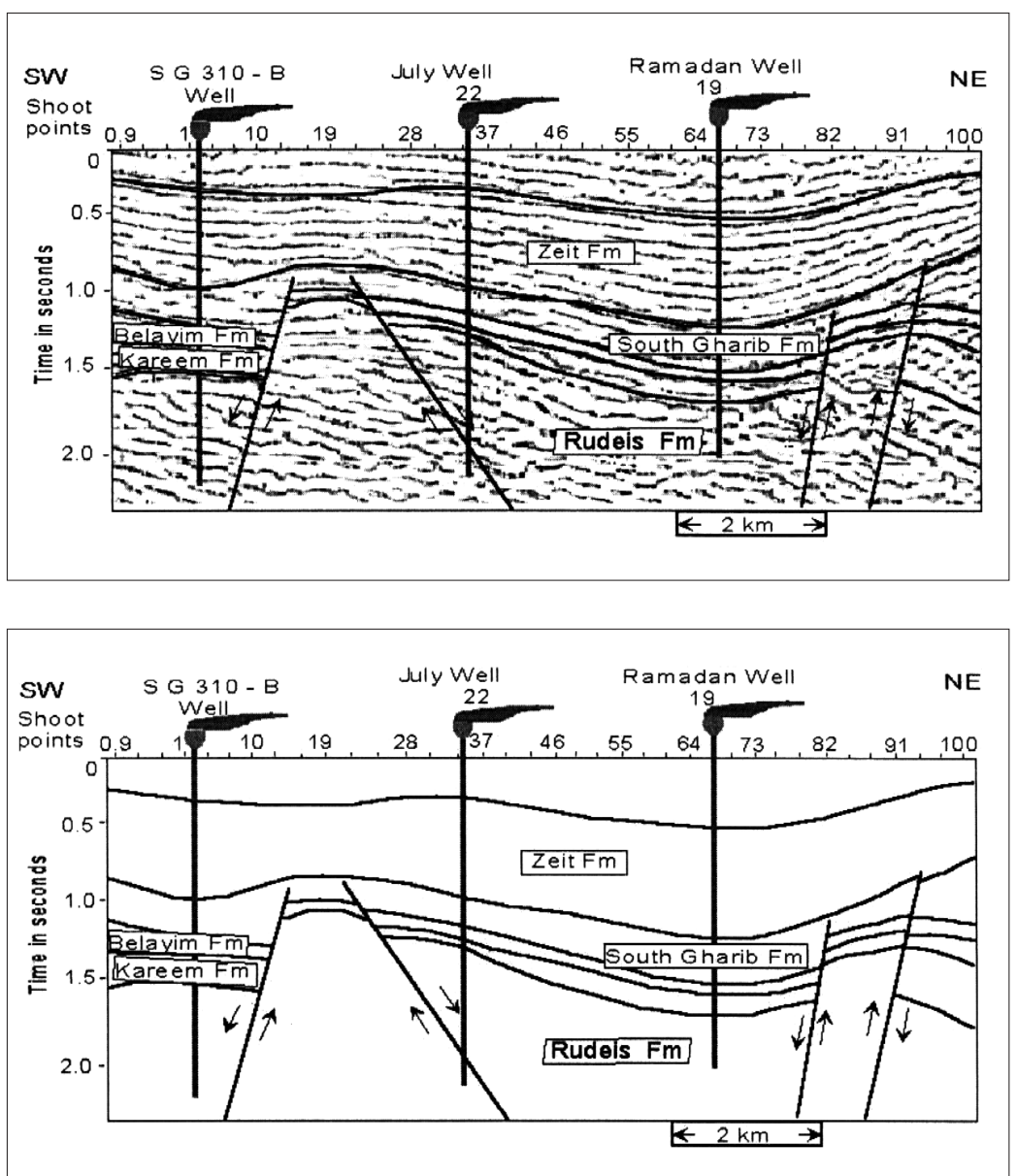

Fig. 17. Interpretation along seismic line MP-70 along Gulf of Suez.

of the depth estimation methods, negative and positive gravity anomalies. These structures have a great importance for oil production and exploration processes.

\section{Seismic interpretations}

Two seismic sections EG-31 and MP-70 were prepared by EGPC trending north westsouth east and north east-south west directions respectively (figs. 16 and 17). These lines were correlated with the vertical veloci- ty $\operatorname{logs}$ to determine the exact horizons (marker beds) and their depth in the studied area.

These seismic sections were used to illustrate the upward continuation and extension of the previously interpreted subsurface structures in the sedimentary sequences.

\subsection{Interpretation along line EG-31}

This line (fig. 16) lies in the western side of the Gulf of Suez and extends for about 20 $\mathrm{km}$ in a northwest-southeast direction. It can 
be noticed that most of the interpreted structures are older than South Gharib Fm. where they extended upward and crossed the older formations (Rudies and Kareem formations), whereas the older structures did not extend upward to cross the younger formations (Belayim and South Gharib formations). The presence of these structures in large numbers indicate that the studied area is affected by active tectonic forces. These structures have been rejuvenated as indicated by their extensions in different time rock units.

\subsection{Interpretation along line $M P-70$}

The length of this line (fig. 17) reaches about $12 \mathrm{~km}$ and extends in a north east-south west direction. This line is affected by four fault lines. It seems that Zeit Fm. (top of the sedimentary sequence) is affected at its lower surface by the interpreted faults, while the older formations (Rudeis, Kareem, Belayim and South Gharib formations) are crossed by these faults.

It is clear that the studied area was affected by the tectonics related to opening of the Gulf of Suez, and the Red Sea. The faults divide the studied area into several numbers of major blocks. These faults are very important in sealing oil traps (e.g., Middle Miocene formations). The depth to these blocks ranges from $0 \mathrm{~km}$ to about $3 \mathrm{~km}$.

\section{Discussion and conclusions}

This study was carried out using different geophysical tools (aeromagnetic, land magnetic, gravity and seismic methods). The data were analysed using the most advanced and suitable techniques. The results of tectonic trend analysis indicate that most of the predominant directions are north $35^{\circ}-45^{\circ}$ west direction that related to Gulf of Suez and Red Sea tectonics, and the least predominant direction is north $10^{\circ}-25^{\circ}$ east, that related to Gulf of Aqaba tectonics. The application of Euler deconvolution with a suitable sliding window to estimate the position of the subsurface intruded magnetic bodies indi- cates that the depth to these bodies ranges from $0 \mathrm{~km}$ to about $3 \mathrm{~km}$ and the magnetic susceptibility ranges between 1 to 3 SI units. Furthermore, application of the analytical signal method confirms the result deduced by the Euler deconvolution technique. The 2.5D technique prints out a complete view for the geometry of the basement surface where the depth ranges between $0 \mathrm{~km}$ to more than $3 \mathrm{~km}$. For the upper investigations of the sedimentary sequence, a geological cross-section was constructed using the well logging data drilled in the studied area as well as two seismic lines. The results indicate that the structures of the area are related to Gulf of Suez, and Red Sea tectonics. These structures extend from the basement rocks upward into the sedimentary sequences and divide the area into several major faulted blocks that have great important in sealing the oil traps. This work is considered a guide line for further exploration process and geophysical works.

\section{REFERENCES}

Atchuta RaO, D, H.V. Ran Babu and P. SANKer NARAYAN (1981): Interpretation of magnetic anomalies due to dikes. The complex gradient method, Geophysics, 46, 1572-1578.

CoOPer, G.R.J. and D.R. CowAN (2003): Application of fractional calculus to potential field data, Explor. Geophys., 34, 51-56.

DAVIS, J.C. (1973): Statistical and Data Analysis in Geology (Jhon Wily and Sons Inc.), pp. 550.

EGPC (Egyptian General Petroleum Cooperation) (1990): Aeromagnetic Map for Sinai Peninsula (scale 1:100 000).

EGSMA (Egyptian Geological Survey and Mining Authority) (1993): Geologic Map Sinai, Egypt (scale $1: 100000)$.

GM-SYS (1995): GM-SYS ${ }^{\circledR}$, Gravity and Magnetic Modelling Version 3.6 (Northwest Geophysical Association Inc., Corvallis, Oregon, U.S.A.).

GRANT, F.S. and G.F. WEST (1965): Interpretation Theory in Applied Geophysics (McGraw-Hill Book Co., New York), 179-191.

Hansen, R.O. and R.S. PAwlowski (1989): Reduction to the pole at low latitudes by weiner filtering, Geophysics, 54, 1607-1613.

HENDERSON, R.G. (1966): A comprehensive system of automatic computer in magnetic and gravity interpretation, Geophysics, 25, 569-585.

Hsu, S.-K. (2002): Imaging magnetic sources using Euler's equation, Geophys. Prospect., 50, 15-25.

IPRG (Institute for Petroleum Research and Geophysics) (ca. 1982): Bouguer Anomaly Map of Sinai (scale 1:100 000). 
LindQuIST, S.J. (1998): The Red Sea Basin Province: Sudr-Nubia(!) and Maqna(!) petroleum systems, U.S. Geol. Surv. Open-File Rep. 99-50-A.

NABIGHIAN, M.N. (1972): Additional comment of the analytic signal of two-dimensional magnetic bodies with polygonal cross-section, Geophysics, 39, 85-92.

NABIGHIAN, M.N. (1984): Toward the three-dimensional automatic interpretation of potential field data via generalized Hilbert transforms. Fundamental relations, Geophysics, 53, 957-966.

Parasnis, D.S. (1997): Principles of Applied Geophysics (Chapman and Hall Publisher, London, U.K.), 5th edition, 21-25.

Patton, T.L., A.R. Moustafa, R.A. Nelson and S.A. Abdine (1994): Tectonic evolution and structural setting of the Suez Rift, in Interior Rift Basins: Tulsa, OK, edited by S.M. LANDON, Am. Ass. Pet. Geol. Mem., 59, 9-55.

Reid, A.B., J.M. Allsop, H. Granser, A.J. Millett and I.W. Somerton (1990): Magnetic interpretation in three dimensions using Euler deconvolution, Geophysics, 55 (1), 80-91.

Roest, W.E. J. Verhoef and M. PILKINGTON (1992): Magnetic interpretation using $3 \mathrm{D}$ analytic signal, Geophysics, 57, 116-125.

STAVREV, P.Y. (1997): Euler deconvolution using differential similarity transformations of gravity or magnetic anomalies, Geophys. Prospect., 45, 207-246.

SURFER (1999): Surfer ${ }^{\circledR}$ Version 7.00, Feb 28, 2000 (Golden Software Inc., Golden, CO, U.S.A.).

SURFER (2002): Surfer ${ }^{\circledR}$ Version 8.00, Feb 11, 2002 (Golden Software Inc., Golden, CO, U.S.A.).

THOMPSON, D.T. (1982): EULDPH - A new technique for making computer-assisted depth estimates from magnetic data, Geophysics, 47, 31-37.

(received June 17, 2003;

accepted December 3, 2003 
